Lautaro Yankas

\title{
Hermana sueño
}

\section{1.- LOS ÁLAMOS}

amanecer nitido enjugó friamente la última estrella-lágrima. Sobre el campo verdoso. las sombras escurridizas. El flojo cerco de los cerros.

Apenas difundida en la alta oquedad despierta la primera mancha de cobalto, el aire, en el afán de jugar a los horizontes y robar alguna pequeña onda azul, cargó alborozado contra la alameda gigante que entraba en el fundo desde el camino público. Fué la unida legión de brisillas de la primera alegria al sentir que el sol está vivo, el viejo sol, y subirá pronto. Los álamos balbucieron aun dormidos, en sus estrechas paralelas rigidas y quietas, blandos murallones. Y, sobrecogidos, seniles y trémulos, despertaron, balbuciendo aquello mismo: una dicha que era pavor. Siempre la bandada juguetona los encontraba dormidos, en empaque mustio. Dero ellos, simples y humildes. y hasta tocados de bondad, no se hubieran rebelado. ¿Con qué valor?

— Vayal... Qué bromita, criaturas. Alegres, muy alegres, las brisillas. Buenos dias... Ya estamos despiertos... Buenos dias.

Uniformados de sombrio verdor, hacen ligeras inclinaciones con sus copas a las brisillas curiosas y rientes. Pero ya huye la alada legión y se reparte hacia los horizontes. porque es la hora del avénturado juego. Los álamos, sin embargo, piensan que las entretienen aún entre ellos, y les murmuran: 
-Ustedes, criaturitas, ¿no esperan al Sol?

Pero luego callan. Su estirada vejez es medio insensible en la primera hora de su despertar. Al fin sospechan que están solos. Estrechos y altos-podridos lanzones aprefujados y flojos. desde el gran camino hasta la tranquera interior,-los álamos aguardan con sumisión igual y uniforme el claro derrame dorado que pondrá en todo ser una vivida dulzura.

Los hombres los saben indistintos y débiles, vulgares y engañosamente erguidos en sus troncos, lamida suavidad gris. Sus formas, sin un capricho, lejos desmesuradamente de aquella agigantada soberbia de los robles que amenazan al cielo con su greña fina, y de la gracia enhiesta de los coigües de cumbre dispersa. Los hombres los enfilan. los juntan en las llanadas, y los peores vientos se divierten con ellos, los humillan. les hincan el terror, los tronchan, los desgarran.

El álamo que bastardea en la falda o la quebrada, muere de soledad. No es lácil que sé crispe alguna vez, si la savia corre y se levanta, fiera de fatalismo, a henchir su tronco harapiento y lastimoso, y su mezquina ramazón estirada. El álamo no ruge. no puede; gime o murmura, es todo. Sólo desea que lo dejen vivir... ¿Pero cómo decirlo? Es el sordo, el prístino deseo. Y confesarlo sería tentar a lo inesperado!... He ahi, pues, el lerror. Los álamos tienen cada noche un sueño negro en que escarabajean horribles sorpresas.

La legión que se prepara a aventurar los sobresalta de muerte en el despertar, dia a dia...

\section{2. - HERMANITA RADIANTE}

El sol al ras de los cerros. Las mil puntitas de oro de los álamos. Neutra claridad, abajo: el sombrio uniforme de la alameda.

Las ágiles vecinas comenzaban a mirar aquella hojita aun dormida al extremo de la frondosa varilla apuntada a lo alto. Cónmovialas el profundo sueño la viva palidez que manchaba 
su afinada punta. Habianla distinguido siempre con ligera insolencia de seres bien nutridos, sanos y perfeclos. Era debilucha, aunque su gracia, bajo un rayo de sol, ninguna hermana pudiera alcanzarla, por sutil que fuera la onda en que mecerse.

- iHermana sueñol-gritó la más próxima.

Asi la llamaban desde un dia en que el sol esluvo cerca de sorprenderla insensible y pesando, rociada por la ventisca recienle, en el fino pecíolo. Desde ese dia. la hermana Sueño salia de su letargo sólo en el instante de recibir el primer toque de sol.

El grito de la hermana próxima fué luego de todas, primero risueño y burlón.

- Hermanita Sueño... Hermanila remolona.

Pero su palidez las aterró y tácitamente redoblaron el Ilamado, pues querian saber... ¿qué?; ansiaban lencrla con ellas en la jubilosa espera matinal. Ráfagas.

- Hermana Sueñol-fué el clamor.

Se estremeció la pequeñila, lemerosa. Las hojas, en ansia. notaron que el despertar era lánguido y que ninguna, ninguna otra sino ella perdicra el firme y bruñido verdor donde el aire dorado deshacia su oleaje de fulguraciones. La luz bajaba por los álamos, queda-su pompa sideral e impasible, - y los millones de hojas temblaban en el milagroso baño, joyantes y medrosas.

La hoja vieja, donairosa aún, aprovechó su vaivén para asomarse al interior de la alameda. Buscó en vano otro tachón de oro. No pudo, entonces, callar un segundo más.

- La hermana Sueño está perdida-dijo con fuerza; y majestuosa se inclinó en la quietud mullida que dejara un golpecillo de viento.

Las demás, abismadas:

- ¿Está perdida?

- Condenada a morir-explicó la mayor.-Todavia no somos viejas y nuestro padre es fuerte. ¿Ustedes no creen? Yo digo que la pequeña no debe morir. ¿Qué dicen, criaturas?, ¿qué murmuran? 
- La hermana Sueño estará enferma un poquilo, nada másgimió otra, esbelta. con sosiego.- ¿No puede haberla pinchado algún elemento travieso? Ella no morirá. Nuestra muerte aun está distante. Pasará el verano, y entonces...

- ¿Cómo charlas! - gritó la mayor-. Olvidémonos de nosotras. y a saber qué tiene la hermanital

- ¿Será enfermedad?

- No; es un misterio. No conocemos otra cosa que nuestro verdor, grato al Sol. Somos felices; pero, en verdad, aquello que no nos explicamos ha de amedrentarnos.

Somos sencillas y felices. No temamos, que lo de nuestra pequeña será sin duda algo de vida, de más vida, y no de muerte o de mal.

- Si, esperemos. Hermana Sucño ha desperfado, es cierto muy triste. Esperemos. Ya el Sol nos alcanza.

-iEl Soll iel Sol!-en murmullo fervoroso.

La pompa y gracia del sol. Las hojas-sus caricias-aturdiéndose más y más. Posesión honda y trágica de los seres sencillos. Hermana Sueño balbuce sonriente y olvidada. Ella va a morir; lo sabe y sabe también el porqué. Además lo mezquino de su materia. en eterna languidez junto a la dicha constante de sus robuslas hermanitas, ha tocado su sentido de la muerte, apenas naciera. Es la más débil, pero esta luz neutra de su vida la serena progresivamente de todo terror.

-El Sol te anima, pequeña-acudió la mayor.

Y las otras:

- Si, estás alegre!

- iY graciosa, más que otros dias!

-Esa palidez te llena de luz. ¡Miren niñas, está bella!

- $\mathrm{Ohl}$ ¿por qué?

-Ah, yo tenia razón. Esperemos, les decia. Pues, mirenla. Está claro que eso es cosa de la vida. Porque a ver, ¿qué es la muerte?

- ¿La muerte?, ¿la muerte?... Yo tengo miedo a la muerte. como nuestro padre el álamo, y como él yo no sé qué guarda esa espantosa palabra. ¿Y la vida? 
-Bah! la vidal Yo siento la vida. ¿Y el Sol?

-Yo siento el Sol. La. la, la, laaa...

-El Sol... el Sol_murmuran en quielud; y de súbilo lodas se inclinan en el aire aplumado por brisas que llegan y huyen.

La viva oquedad celeste. Tierra intensa de primavera.

En la quielud, la hermana Sueño fija su sonrisa de oro y canta quedo:

- Voy a morir, hermanas.

- ILocal... |Hermana Sueñol lú vives vida de belleza. ¿Oyes? Tú sabes lo que es eso. Estás creada de una nada de materia y de mucha luz. Te amamos porque eres tierna y grácil y tienes la única belleza. ¡Eres sólo lú!

-Locas-sonrie la pequeña.-Son sencillas ustedes y tienen la vida pura. ¿Para qué sirve la belleza si lo demás se ha descuidado? Los seres sencilios y aquellos profundos y grandes se entregan. $y$ aún saben pedir la muerte. Ustedes no la temerán.

- Maravillosa hermanila_cuchichcó una a su vecina.

- Es la hermana radiante. ¿Dice que los sencillos y los genios?...

-Eso dice. Es la verdad.

- Es la belleza, primero.

- Pequeñila, joya de Sol-dice la mayor-d dime si ayer el Dios le encontró dormida, porque, cierlo es, nosolras no te despertamos; ¿recuerdas?

- Si; el Sol me halló dormida. hermana.

Silencio. Al pie-luz-de los álamos, el potrero.

-Tuve un suerio. hermanila, y por él sé que eso es la muerte. El Sol toca de muerte a aquella que no lo aguarda despierta y ferviente... ¿Este sueño lo fuve porque ibas a morir?

La pequeñila Sueño, iluminada y grácil. es leve llama de oro danzando en el vago abismo del aire. Llegó. quién sabe de dönde, una ráfaga fresca que doblegó la inmensa alameda al Sol. La pequeñita oyó en su ser ya tenue, un como lejano chasquido. 
Desprendida, picó un segundo en el aire y quedó meciéndose a dislancia.- -Sus hermanas: la mudez del ansia desconocida. - Bajó sin apremio en el suave abismo, juguetona de gracia y de luz. Su sonrisa clavada al Sol. 